\title{
A study on the eco-design of consumer electronics
}

\author{
Jianfang Zong*, Jianwei Tian, Dongfeng Gao, Liang Chen \\ China National Institute of Standardization, No.4 Zhichun Road, Haidian District, Beijing, 100084
}

\begin{abstract}
This paper first introduces the definition, origin and development of product eco-design, compares the relations between eco-design and traditional design. This paper then explains the purpose, principles, ideas and contents of eco-design of consumer electronics, and expounds the requirements, procedures, key points and methods of eco-design of consumer electronics. Finally this paper points out the deficiencies and shortages, and development trend of eco-design of consumer electronics.
\end{abstract}

\section{THE DEFINITION, ORIGIN AND DEVELOPMENT OF PRODUCT ECO- DESIGN}

Product eco-design means that the impact of the raw materials selection, production, sales, usage, recycle, treatment and other links upon the resources and environment shall be systematically considered at the product design and development stage as per the lifecycle ideas, strive to minimize the resources consumption during the product lifecycle, use the raw materials with little or without anytoxic and harmful substance if possible, and reduce the production and emission of pollutants, thus realize the target of environmental protection.

Eco-design is a new concept in the field of environmental management field proposed by Holland's Public Authority and United Nations Environment Programme (Hereinafter referred to as UNEP). It integrates with economics, environment, management, ecology and other subject theories, and is deemed as the effective manner to promote the circular economy development model. Eco-design is also called "green design" or "environmental design". The eco-design activity mainly includes the meanings of two aspects, namely, to reduce the resources consumption and realize the sustainable development strategy from the perspective of environmental protection, and to lower the cost, to reduce the potential liability risks and enhance the competitiveness from the commercial perspective [1].

Upon being put forward, the concept of eco-design is highly regarded by the government and business circles[2]. In 1992, the U.S. Technical Bureau of Investigation published the Green Product Design Report regarding the design of Environmental Conscious Product (ECP), and also established the ECP research center, carrying out the technical development of ecodesign[3]. Germany's famous Wuppertal Institute, Leiden University in the Netherlands, Sustainable Center of University of Surrey in England, and Cranfield,
Surrey, Brunel, and Manchester Metropolitan and other universities, respectively adopt the variable methods to develop the new eco-design tools aiming at different industries (such as electronics, appliances, packages, and furniture industries, and etc). At the enterprise level, Dutch Phillips, American AT\&T, and German Benz Motors Company, and other companies have successively made the attempts regarding the product eco-design, and achieved the success. The practice shows that the eco-design can decrease the environmental load by $30 \% \sim 50 \%$. Besides, in recent years, the environmental standards and policies have already caused the substantial impact on the existence and development within the international investment and trade fields. The Double Green Directives enforced by the EU affects about 100 kinds of end products. Among which about $20 \%$ belongs to "Made in China", while China's mechanical and electrical products with the value of USD 37.1 billion will face such an environmental protection barrier. In July, 2005, EU enacted the Framework Directive for the Eco-design of Energy Using Products(EUP Directive). The EUP Directive is intended to create a complete regulatory framework as the basis of product eco-design, while it also introduces the life cycle idea to the product design link, intends to propose the environmental protection requirements to the products at every link during the entire life cycle ranging from the design, manufacture, usage, post processing to final elimination, by starting from the origin, and comprehensively monitoring the product's impact upon environment, to reduce the environmental damage. Facing the surging green technology tide, Chinese companies can improve the international competitiveness of products and realize the goal of sustainable development only through earnestly conducting the eco-design and continuously enhancing the environment-friendly level of products. Therefore, the study on the current development status of product eco-design both at home and abroad and learning ecodesign experiences of successful enterprises have a very

\footnotetext{
* Corresponding author: zongjf@enis.gov.cn
} 
important practical and strategic meaning for China's implementation of scientific outlook on development.

China has carried out the product eco-design works as follows: In October 2011, the State Council enacted the opinions on strengthening major environmental protection work, where "promoting the industrial product eco-design"was taken as the significant measures of environmental protection, while it was proposed for the first time to carry out the eco-design works at the state level. In February 2013, Ministry of Industry and Information Technology, National Development and Reform Commission, and Ministry of Environmental Protection jointly released "The guidance on carrying out the eco-design of industrial product". In July 2014, Ministry of Industry and Information Technology released "The notice on organizing the implementation of establishment works of industrial product Eco-design demonstration enterprises". On May 8, 2015, the State Council released "Made in China 2025 " , and "Supporting the enterprises to develop the green products, promoting the eco-design and guiding the green production and green consumption" was proposed. In July 2016, the State Council issued "The 13th Five-year plan on scientific and technological innovation", and it is proposed to construct the product life cycle-based green manufacturing technology system. In July 2016, the Ministry of Industry and Information Technology issued the "Industrial green development plan (2016-2020)", where it is proposed to strengthen the green management of product life cycle, to establish one hundred green design demonstration enterprises, one hundred green design centers, one thousand green demonstration factories, and one hundred green park zones, and strive to develop and promote ten thousand types of green products. In September 2016, Ministry of Industry and Information Technology released "The green manufacturing engineering implementation guideline (2016-2020)", where it is proposed to establish and improve the life cycle of green standards, to develop and promote the ten thousand types of green products, to establish the green supply chain management system, to build the product life cycle basic database, and to actively carry out the third-party service institution on green manufacturing consultation, accreditation, training and other services, as per the product life cycle green management requirements. In September 2016, Ministry of Industry and Information Technology released "The notice on building the green manufacturing system", where it is proposed to use the promotion of the whole industrial chain and product life cycle green development as the objective, the enterprises as the building entity, the open and transparent third-party assessment mechanism and standard system as the basis, and green factory, green product, green park zone, and green supply chain as the main contents. In December 2016, the State Council released "The opinions on establishing a uniform system for standards, certification and labeling of green products", where it is proposed to establish the integrated evaluation index system based on the product life cycle. In December 2016, the State Council released "The promotion plan on extended producer responsibility system", where it is proposed to extend the resources and environmental responsibilities of products undertaken by the producer from the production link to the product design, circulation and consumption, recycling, waste disposal and the whole life cycle. However, China is still desperately in need of the operable standards and tools. Therefore, it is very urgent to develop and construct a set of eco-design product system with the strong practicability and extensive applicability.

\section{RELATIONS BETWEEN ECO-DESIGN AND TRADITIONAL DESIGN}

The eco-design stresses that the possible environmental problems that may be brought by the products shall be considered, and the concerns of environmental problems and traditional design process shall be combined. In this process, the basic procedures of product development process do not have any change due to considering the environmental factors, but the designer is required to add the environmental impact assessment of products during the traditional design process, and the new design is required to reduce the environmental impact of products. Therefore, the designers shall collect all types of environmental information related to the designed products, screen out the available useful information, and also reflect the understanding of such information on the design of new products. During the eco-design process, the designers will often encounter the problem of whether to choose satisfying the environmental requirements or other requirements, for instance, during the selection process of raw materials, whether to choose the materials that may minimize the environmental impact or the materials that is practical but is harmful for environmental protection. During the process of traditional design, it is often not required for the designers to consider these problems. The comparison between product eco-design and traditional design methods is as shown in Table 1.

Table 1 Comparison between Product Eco-Design and Traditional Design Methods

\begin{tabular}{|c|c|c|}
\hline $\begin{array}{c}\text { Compariso } \\
\text { n factor }\end{array}$ & Eco-design & $\begin{array}{c}\text { Traditional } \\
\text { design }\end{array}$ \\
\hline Design basis & $\begin{array}{c}\text { Environmental } \\
\text { efficiency, product } \\
\text { performance, quality } \\
\text { and cost requirements }\end{array}$ & $\begin{array}{l}\text { Performance, } \\
\text { quality and cost } \\
\text { requirements }\end{array}$ \\
\hline Designer & $\begin{array}{c}\text { Traditional designer, } \\
\text { ecologist, and } \\
\text { environmentalist }\end{array}$ & $\begin{array}{c}\text { Traditional } \\
\text { designer }\end{array}$ \\
\hline Design idea & $\begin{array}{l}\text { At the product } \\
\text { speculation and design } \\
\text { stage, it is required to } \\
\text { consider reducing the } \\
\text { energy consumption, } \\
\text { recycle the resources } \\
\text { and protect the } \\
\text { ecological } \\
\text { environment. }\end{array}$ & $\begin{array}{l}\text { It scarcely or not } \\
\text { considers the } \\
\text { energy saving, } \\
\text { resources } \\
\text { recycling and } \\
\text { ecological } \\
\text { environmental } \\
\text { impact. }\end{array}$ \\
\hline
\end{tabular}




\begin{tabular}{|c|c|c|}
\hline $\begin{array}{c}\text { Design } \\
\text { process }\end{array}$ & $\begin{array}{c}\text { During the product } \\
\text { manufacturing and } \\
\text { usage process, it is } \\
\text { required not to } \\
\text { produce the toxic by- } \\
\text { products if possible. It } \\
\text { is required to produce } \\
\text { the least wastes by } \\
\text { utilizing the } \\
\text { detachability and } \\
\text { recyclability of } \\
\text { products. }\end{array}$ & $\begin{array}{c}\text { Recycling is not } \\
\text { considered } \\
\text { during the } \\
\text { manufacturing } \\
\text { and usage } \\
\text { process of } \\
\text { products, while } \\
\text { the products are } \\
\text { thrown away } \\
\text { after use. }\end{array}$ \\
\hline $\begin{array}{c}\text { Design } \\
\text { purpose }\end{array}$ & $\begin{array}{c}\text { Design for } \\
\text { environment }\end{array}$ & $\begin{array}{c}\text { Design for } \\
\text { manufacturing }\end{array}$ \\
\hline $\begin{array}{c}\text { Products } \\
\text { obtained }\end{array}$ & $\begin{array}{c}\text { Ecological products or } \\
\text { green products }\end{array}$ & $\begin{array}{c}\text { Traditional } \\
\text { products }\end{array}$ \\
\hline
\end{tabular}

As shown in Table 1, the fundamental difference between the product eco-design and traditional design is the variation of design idea [4]. The relations between product eco-design and traditional design: Someone calls the traditional design as the "cradle-to-grave" design, mainly considering the basic properties of product required by the customer, but neglecting the environmental properties of the product. It scarcely considers the usage and maintenance cost of product at the usage stage, and does not consider the disposal cost after the termination of product life. Starting from the product life cycle, the product eco-design considers the environmental impact of product at each stage of its life cycle, especially, how to redesign the recovery, regeneration and recycling of abandoned product after the product is abandoned, which can minimize the environmental impact of abandoned product, and maximize the recycling degree of resources. Therefore, the product eco-design is also called as "cradle-tocradle"design. The eco-design requires converting the traditional production model to the "Ecologicalized" production model, namely, forming the raw materialsproduct-residue-product cycle, and gradually realizing the ecologicalization process [5].

\section{PURPOSES, PRINCIPLES, IDEAS AND CONTENTS OF ECO-DESIGN OF CONSUMER ELECTRONICS}

Purposes of eco-design of consumer electronics: it is intended to minimize the environmental pollution caused by the consumer electronics and enhance the recyclability rate of consumer electronics, so as to reduce the adverse environment effect caused by the consumer electronics during their whole life cycle, and develop the more ecologic, more economic and sustainable consumer electronics system.

Principles of eco-design of consumer electronics: while continuously improving eco-design idea and developing the practice, the eco-design is carried out and mainly based on the following principles at present [6]:

(1) Demand-oriented principle. The demandoriented eco-design shall adhere to the following principles: From the holistic perspective, it shall integratedly consider the resources comprehensive utilization demand of consumer electronics and their corresponding systems; from the process perspective, it shall comprehensively consider the environmental demands of consumer electronics at each stage of their life cycle, especially, the environmental demand during the process of usage and abandonment; from the functional perspective, it shall adopt the custom design, avoid the function waste, and make the functions of consumer electronics properly reflect the system demand.

(2) Technical feasibility principle. The technology-based eco-design shall adhere to the following principles: For design, it shall give preference to the advanced design technology. Under the premise that the technical performance index of consumer electronics, it shall pursue the enhancement of environmental index of consumer electronics. Based on the feasible manufacturing technology, it shall adopt the relatively mature environmental technology, minimze the complexity of integration technology, and realize the organic integration with the design technology.

(3) Environment-friendly principle. The environment protection targeted on eco-design shall adhere to the following principles: During the eco-design process of consumer electronics, it shall give preference to the environment-friendly advanced design technology, ensuring the safety of consumer electronics during the processing and manufacturing, usage and maintenance, final disposal and other processes. Besides, it shall not only realize the functions of consumer electronics, but also pursue the reducing, reusing, and recycling, and improve the environment impact of equipment life cycle, especially, the environment impact during the usage and abandonment handling process. Besides considering the environmental impact of consumer electronics themselves, it shall also focus on the enhancement of resources comprehensive utilization performance of consumer electronics, reducing the secondary pollution.

(4) Economic rationality principle. The economy-premised eco-design shall follow the following principles: it shall comprehensively consider the environmental benefits of consumer electronics, including the environmental efficiency and cost, give consideration to the environmental benefits of enterprises, customers, and society, and adopt the environmental technology of economic rationality.

(5) Principle on the basis of the theory of circular economy. The circular economy is a generic term for the reducing, reusing and recycling activities conducted in the process of production, circulation and consumption.The eco-design of consumer electronics shall consider facilitating the handling of wastes produced at each phase of the life cycle of consumer electronics, including the disassembly and recycling of products abandoned after the circulation and consumption, especially the reusing and recycling of abandoned products, elements and materials.

(6) Principle according to the theory of industrial ecology. From the perspective of industrial ecology, although the traditional green design has already considered the product design from the environmental protection perspective, there are still considerable limitations. The eco-design of consumer electronics not only refers to recycling, reusing, detachability and 
modularization, but also actually use less or does not use the materials in the natural world. The theory of industrial ecology explains the following principles that shall be adhered to by the product eco-design: it shall follow the design principle of respecting the nature and whole priority. Meanwhile, it shall follow eco-design principle of emphasizing on the environmental coordination and fully utilizing the natural resources, the principle of playing the natural ecological adjustment function in mechanism design, the participatory and economic principle of eco-design, and ruralization, convenience and humanity prinicple.

(7) Principle in accordance with life cycle theory. The life cycle theory of consumer electronics is to consider the environmental impact at the design stage of consumer electronics, raw materials extraction, processing, production, packing, transportation, distribution, usage, abandonment, and post-handling and disposal, and other stages, and minimize the environemntal impact via the eco-design. The principle and requriments of life cycle assessment shall refer to national standards GB/T24040[7] and GB/T 24044[8]. The consumer electronics may include a series of environmental factors (for instance, producing the emissions and consuming the resources), which further cause the environmental impact (for example, air, water and soil pollution and climate change, and etc). To a great extent, the environmental impacts of consumer electronics are caused by the input and output of materials and energy at each phase of life cycle of consumer electronics.

(8) Consideration of the requirements of laws, regulations and stakeholders. The eco-design of consumer electronics shall be enforced within the framework required by the laws, regulations and stakeholders, while the relevant changes of such requirements shall be periodically checked and understood when the eco-design is implemented. The requirements of laws and regulations and stakeholders shall include the following contents: restrictive requirements and liability of national and international laws and regulations, technical standards and voluntary agreements, market or consumer demands, development trend and expectation, desires of society and investors.

Ideas of eco-design of consumer electronics:

(1) To reduce the physical input: the design of consumer electronics shall consider the minimum physical input and energy consumption of the whole product life cycle and whole industrial production chain. In particular, the reduction of physical input refers to provide the same economic function, but relatively or absolutely reduce the usage amount of materials and lower the energy consumption.

(2) To emphasize on the functional economy: The consumer electronics are a kind of means to provide the specific function to consumers, while the consumers only concern about the functions provided by the products. Therefore, it is recommended to attract the consumer attention from concerning about the product features to concerning about service properties, and further seek the chance and possibility of industrial ecology, namely, it is recommended to substitute the production activities that consume a lot of materials and energy through providing the services, so as to reduce the usage amount of resources and waste emissions.

(3) To seek the physical substitute: The new and environment-friendly substances shall be used to substitute the old substances. For example, polymeric materials are used to substitute the steel products while the optical fiber is substituting the copper cable, and others.

Contents of eco-design of consumer electronics: It is mainly concentrated at four aspects.

(1) The raw materials shall be selected from the ecological perspective. At present, the raw materials in ecological design shall be mainly selected from the following aspects: it is required to prevent from using the toxic and hazardous materials and additives, and consider the application of substitute material. It is required to prevent from using the raw materials that are non-renewable or take a long time to recover, such as fossil fuel and etc. It is required to try to use the equivalent and recyclable raw materials, so as to facilitate the recycling and minimize the energy consumption of raw materials during the cutting and production process. It is required to try to use the recyclable materials to reduce the usage amount of new materials and create market for recyclable materials. It is required to consider trying to reduce the usage amount of raw materials, so as to reduce the volume and weight of product and facilitate the transportation and storage. Furthermore, it is also required to adopt the low energy raw materials.

(2) The eco-design of consumer electronics: It is required to integrate the functions of consumer electronics, optimize the structure of consumer electronics and functions of parts of consumer electronics, and also to reduce the energy consumption of consumer electronics during the usage process. Besides, the package design of consumer electronics shall prevent from excess and luxury. It is required that the consumer electronics shall be easy to maintain, repair and recycle.

(3) The eco-design of production process: It is required to select the production technology with less environmental impact and establish the ISO14001[9] environmental management system.

Eco-design of industrial ecological system: The industrial production process is assimilated as a natural ecological system which will make the comprehensive balance upon the systematic input (energy and raw materials) and output (product and waste), promote the evolution of industrial system and make it to convert from the low level ecosystem to the third level ecosystem.

\section{ECO-DESIGN REQUIREMENTS OF CONSUMER ELECTRONICS}

The life cycle phases of consumer electronics considered by eco-design shall include: the acquisition, selection and usage of raw materials; product manufacturing; package, transportation and distribution; maintenance 
and repair; product usage; and recycling and disposal.At each stage of life cycle, the environmental factors that shall be counted shall include: the consumption of resources and energy; emission types and amount of hazardous materials; the pollution caused by noise, radiation and electromagnetic fields, and other physical effects; the produced waste mateirals; and reclaimation (reusing, recycling and energy recovery, and etc). The production enterprises may equip the measuring instrument of energy as per the requirments of GB 17167[10], while product energy efficiency index shall conform to the requirements of GB 26920.1[11]. The safety design, electromagnetic compatibility design, particular requirements of eco-design, the inspection methods and requirements of restricted substances, product package, restricting excessive packaging and recyclability rate shall respectively conform to requriements of GB 4706.102[12], GB 4343.1[13], GB/T 23109[14], GB/T 26125[15], GB/T 26572[16], GB/T 1019[17], GB/T 31268[18], and GB32355.1[19]. The laws and regulations and other techncial requirements include not only the requirements of compulsory environmental protection laws and regulations, such as energy efficiency standards, noise and electromagnetic compatibility, production process related environmental protection regulations, and the limit value requirements of recovery rate and recycling rate, but also the requirements of noncompulsory environmental protection laws and regulations, such as hazardous substance requirments of materials and package. Besides, there are also some ecological technical requirements that are not definitely specified by the laws and regulations, such as minimizing the quantity of parts, types and amount of materials, enhancing the standardization and universalization rate, adopting the equal life design principle if possible, and being easy to maintain and repair, dismantle, store and deliver.

\section{PROCEDURES AND KEY POINTS OF ECO-DESIGN OF CONSUMER ELECTRONICS}

Eco-design procedures: The eco-design procedures of consumer electronics may be divided into demand analysis, concept design, structure design and detailed design, while the design procedures at variable phases have their own eco-design key points.

Key points of eco-design:

(1) Key points of eco-design in demand analysis are to consider the economic and policy impacts of ecologization. In the market and enterprise situation analysis, the economic and policy impacts of ecologization shall be considered. The environmental policy of organization is as shown in GB/T 24001[20]. Besides, it is required to consider th new technology and research achievements of new technology. In the innovative design scheme of discovery and selection of consumer electronics, the new ecological technology and research achievements shall be considered according to its feasibility and maturity. It is required to consider the environmental and regeneration problem of consumer electronics. In demand analysis, the environmental and regeneration problem of consumer electronics shall be considered, and the environmental demands shall be incorporated into the demand list. Prior to the concept design of consumer electronics, the generalized demand analysis of product shall be made, while the theory of life cycle shall be applied to analyze the manufacturing, usage, reusing after the abandonment and disposal conditions of product and its parts and components, which shall include the following aspects: external demand analysis (user demand analysis, distributor demand analysis, and supplier demand analysis, and etc); internal analysis; and stakeholder demand analysis.

(2) Key points of eco-design in concept design: It is required to select the eco-friendly working principle. In the process of determining the solution of working principle, it is required to select the eco-friendly working principle, based on the list of working principles and all types of the variant original understanding, and by adopting the scientific comparison method. Besides, it is required to select the lightweight working structure. In the process of determining the solution of working structure, it is required to select the lightweight working structure, especially emphasizing on the lightweight of moving parts, based on the solution of working principle and by adopting the scientific comparison method. Furthermore, the ecological criteria shall be added into the assessment criteria. In the assessment criteria of concept design, except for the technical criteria and economic criteria, the ecological criteria shall also be added.

(3) Key points of eco-design in structural design: It is required to adopt the renewable materials. On the selection of raw materials of parts, it is required to give preference to the adoption of renewable materials and to enhance the comprehensive utilization performance. During the process of optimization, refinement and enhancement of structure design scheme, it is required to make the enhancement of comprehensive utilization performance of consumer electronics as one of the primary optimization objectives, and to simplify the structure of consumer electronics and parts and components. During the process of structure design, it is required to properly simplify the assembly and disassembly procedure, so as to facilitate the maintenance and final disposal of consumer electronics. It is required to facilitate the clear disassembly of nonrenewable materials. During the structure design process, it is required to make the non-renewable materials become relatively independent and clearly disassembled in structure, so as to facilitate the final disposal of consumer electronics. Furthermore, the environmental criteria shall be added into the assessment criteria. In the assessment criteria of structure design, except for the technical criteria and economic criteria, the environmental criteria shall also be added.

(4) Key points of eco-design in detailed design: it is required to provide the ecological requirements of key process. In the detailed design of production process, it is required to identify the key process of environmental impact, and also provide the ecological requirements of key process. Under the premise that the 
relevant laws and regulations shall be satisfied, the following factors shall be mainly considered to weight and optimize the key process: technical process; processing equipment, inspection equipment, tooling, tools and mould; selection and use amount of auxiliary materials; the concentration limits of toxic and hazardous substances in the auxiliary materials; and the energy consumption, noise, pollutant discharge and others during the manufacturing process. Besides, it is required to provide the comprehensive utilization instruction. Except for the general instructions, it is also required to provide the comprehensive utilization instruction in the relevant documents. It is required to explain the assembly and disassembly sequence. In the description of detailed design, except for the assembly description, it is also required to add the disassembly description, and to explain the assembly and disassembly sequence in the relevant documents, and the disassembly methods of non-renewable materials. In the disassembly description of detailed design, it is required to highlight the disassembly of non-renewable materials, and also to explain the disassembly methods of non-renewable materials in the relevant documents. Finally, it is also required to provide the recycling description of consumer electronics, parts and components. There shall be the final disposal description in the detailed design, where it is required to provide the recycling description of consumer electronics, parts and components.

\section{ECO-DESIGN METHODS OF CONSUMER ELECTRONICS}

In this section, it explains the life cycle design method and modular design method, which may be either independently applied or applied in combination. The methods adopted by the eco-design may include but not be limited to such methods.

(1) Life Cycle Design Method

The life cycle design shall be aimed at the raw materials acquisition, processing and manufacturing, usage and maintenance, enhancement, final disposal and other stages of life cycle. The systematic design shall be made by using the enhancement of resources utilization rate and improvement of environmental impact as the objective and continuous enhancement as the means. The life cycle design shall consider the demand analysis, concept design, structure design, detailed design and other whole product design process. Besides, it may either be combined with the modular design and other design methods, or adopt the parallel design. The usage phase is the major link of life cycle of consumer electronics, which shall use the enhancement of resources utilization rate, reduction of operation failure times, and shortening the downtime of maintenance and repair as the key objectives of life cycle design.

The design process of life cycle mainly includes the demand breakdown, design analysis, objective identification, technical $\mathrm{R} \& \mathrm{D}$, design refinement, and life cycle assessment, while the life cycle assessment is correlated to the procedure of the basic process. As shown in Figure 1, it will break down the ecological demand to each stage of life cycle of consumer electronics, analyze the present status of product ecodesign, identify the key design refinement objectives, explore the feasible technical achievement scheme, conduct the environmental improvement on the product design, and carry out the life cycle assessment to the consumer electronics, so as to support the procedure of basic process. The assessment principle of life cycle is as shown in GB/T 24040.

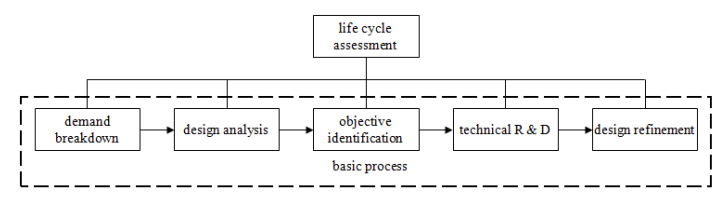

Fig. 1. Major Process of Life Cycle Design of Consumer Electronics

The life cycle design is the generic technical method of eco-design of consumer electronics, while its major ecological functions are as follows:

a) To consider the ecological problems from the life cycle perspective, so as to improve the overall performance of eco-design;

b)To identify the key objectives and major links, so as to improve the pertinence;

c) To carry out the technical R\&D by centering on the major problems, which is in favor of breaking through the key technology of eco-design;

d)To enhance the eco-design level of the whole life cycle and its each phase.

(2) Modular Design Method

Based on the comprehensive analysis of customer demand, and as per the systematic engineering idea, the modular design is intended to break down the customer electronics to the serialized and generalized mould, with independent functions and being easy to reuse and vary, and obtain the personalized product.

The modular design shall face the whole consumer electronics family, fully utilize the modular similarity and reusability, and effectively control the diversity of consumer electronics, which not only allows the customers to feel the inner diversity of consumer electronics, but also allows the enterprises to feel the inner diversity of consumer electronics.

The modular design may be divided into the modular design of new consumer electronics and existing consumer electronics. The former refers to the innovation of product structure and mould, while the latter refers to the rationalization of product structure and mould. It is suggested to adopt the modular design with information support.

The modular design process mainly includes the modular division, modular standardization, product modeling, configuration design, variant design, and modular assessment, while the life cycle assessment is correlated with the procedures of modular design process and custom design process. As shown in Figure 2, the modular division, modular standardization, and customer electronics modeling constitute the product modular design process, while the configuration design and variant design constitute the product custom design 
process. The product modular assessment shall be conducted to support the procedures of modular design process and custom design process. The modular assessment mainly has the comparison value for the equivalent products.

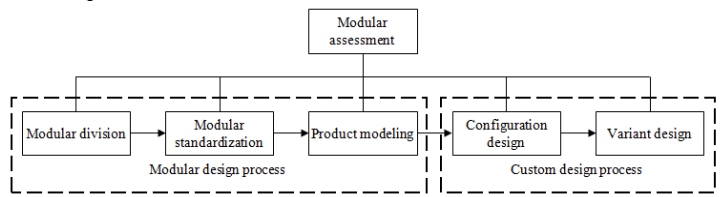

Fig.2. Major Procedures of Modular Design

Modular design is the generic technical method of eco-design of consumer electronics, while its major ecological functions are as follows:

e) To support the rapid custom design, satisfy the customer's personalized demand, and avoid the waste of manufacturing resources;

f) To enhance the modular mass production, realize the economies of scale, and give full play to the efficiency of manufacturing resources;

g)To be easy to use and maintain, reduce the equipment breakdown loss and extend the product service life;

h) To realize the detachability, and be easy to reuse the spare parts;

i) To support the environmental refinement of product through the modular refinement.

\section{DEFICIENCIES AND SHORTAGES OF ECO-DESIGN OF CONSUMER ELECTRONICS}

At present, the eco-design of consumer electronics worldwide is still at the early development phase. Similarly, the eco-design of China's consumer electronics also just starts, and is still not mature, and has many deficiencies and shortages. Firstly, the comprehensive value system to guide the eco-design of consumer electronics is still not developed. The ecodesign of consumer electronics needs to comprehensively consider the aesthetic value, economic value, social value and ecological value, so as to realize the aesthetic-economic-ecological-social integrated function of product. Secondly, the supporting policy, laws and regulations, and other external environment shall be further developed and improved. To a great degree, the effective enforcement of eco-design of consumer electronics depends on the support of policy, laws and regulations, and other external environment. Although it seems that the eco-design of developed countries is the voluntary action of enterprises, the promotion of government laws, regulations and policies are also indispensible, and the institutional assurance to motivate the eco-design is the significant premise of promoting the enterprises to implement the eco-design. At present, all types of institutional designs for promoting the eco-design still need to be improved. Thirdly, the operable eco-design enforcement framework of consumer electronics is still in the process of establishment. At present, the eco-design still neither has the fixed program to follow, nor lacks the unified assessment criteria. Meanwhile, the eco-design extensively involves many fields, while the designers generally consider problems from their own professions, and cannot properly combine the other relevant disciplines to make further and more extensive systematic study, and lacks the lateral integration. At the operation level, although the academic circles have already proposed the basic framework of eco-design, the lateral integration is still not made among the variable disciplines, while the operable, unified enforcement framework is not formed either. Fourth, there is no adequate education and training.

\section{DEVELOPMENT TREND OF ECO- DESIGN OF CONSUMER ELECTRONICS}

The eco-design of consumer electronics not only reflects the ecological concerns of human beings in the design field, but also reflects our richer and deeper understanding about the relationship between human and nature in a more significant sense, and is the strategic response to our sustainable development strategy in the design field. Therefore, the further development of ecodesign of consumer electronics will necessarily depend on our deeper understanding of nature, ourselves and the relationship between human and nature. It will continue to develop and deepen in the following areas: it is required to further understand and grasp the natural laws, and introduce the bionics to the eco-design. It is also required to strengthen the inter-disciplinarity, and enrich the contents of eco-design, to continuously develop and apply the advanced technical means to implement the eco-design. Furthermore, it is also required to emphasize on the combination of macrocosm and microcosm from the systematic perspective, while the education and training of eco-design will continuously promote the popularity and development of eco-design.

\section{CONCLUSION}

Eco-design of consumer electronics is to promote enterprises to reduce the usage of resource, decrease energy consumption and pollutant and cut down greenhouse gas emissions from the source. Eco-design of consumer electronics is also to improve the processing technique to develop in the direction of energy saving, low carbon and green technology, thus become the important driving force for promoting industry transformation and upgrade. On the premise that the product can meet the functional requirement of the user, in the process of the whole life cycle of design, production, usage, waste disposal and so on, ensuring the high efficiency of the resource and energy utilization of the product, biodegradability, biological safety, innocuity and harmlessness or low toxicity, low pollution and low emission is the core idea to develop eco-design of the consumer electronics. The ecological damage caused by the development of modern science and technology needs to be directly confronted by people, and we can make smarter and more ecological decisions for users through ecological products. 


\section{Acknowledgements}

This paper is funded by National key research and development plan project "Research on key technology standards of eco-design for consumer electronics and other important products"(2017YFF0207901).

\section{References}

1. ZONG Jianfang, CHEN Jianhua, Comparative Analysis on Domestic and International Mechanismof Product Ecological Evaluation: China National Institute of Standardization, 2017, (15): 5458

2. JIN Min, The Present Situation and Future Trend of Eco-Design: Appliance Science \& Technology, 2009(9), p48-50

3. JIANG Xinying, JI Ying, Overview of International Studies on Theories and Practices of Product EcoDesign: Green Economy (Chinese Version), 2006 (2), p77-80

4. WANG Shoubin, WU Feng, LIU Jinru, Industrial Ecology: Chemical Industry Press, 2005.11: 113

5. LI Gang, LIU Chao, History of Modern Design: Hunan People's Publishing House, 2007.9: p113-114

6. YANG Jianxin, Methodology of Product EcoDesign: Chinese Journal of Environmental Engineering, 1999 (1), 67-72

7. GB/T 24040Environmental Management-Life Cycle Assessment-Principles and Framework

8. GB/T 24044 Environmental Management-Life Cycle Assessment-Requirements and Guidelines

9. ISO 14001 Environmental Management SystemRequirements with Guidance for Use

10. GB 17167 General Principle for Equipping and Managing of the Measuring Instrument of Energy in Organization of Energy Using

11. GB 26920.1 Minimum Allowable Values of Energy Efficiency and Energy Efficiency Grades of Commercial Refrigerating Appliances-Part 1: Refrigerated Display Cabinets with Remote Condensing Unit

12. GB 4706.102 Household and Similar Electrical Appliances-Safety-Particular Requirements for Commercial Refrigerating Appliances with an Incorporated or Remote Refrigerant Condensing Unit or Compressor

13. GB 4343.1Electromagnetic CompatibilityRequirements for Household Appliances, Electric Tools and Similar Apparatus-Part 1: Emission

14. GB/T 23109Eco-Design of Household and Similar Electrical Appliances-Particular Requirements for Refrigerator

15. GB/T 26125 Electrical and Electronic ProductsDetermination of Six Regulated Substances (IEC 62321: 2008, IDT)
16. GB/T 26572 Requirements of Concentration Limits for Certain Restricted Substances in Electrical and Electronic Products

17. GB/T 1019 General Requirements for the Package of Household and Similar Electrical Appliances

18. GB/T 31268Restricting Excessive Packaging for Commodity-General Rule

19. GB/T 32355.1 Assessment Values of Recyclability Rate for Electrical and Electronic Products-Part 1: Room Air Conditioners and Household Refrigerators

20. GB/T 24001Environmental Management SystemsRequirements with Guidance for Use (GB/T 240012004, ISO 14001: 2004, IDT) 